Гойнов Иван Владимирович, Зритнева Елена Игоревна

\title{
ПЕДАГОГИЧЕСКОЕ СОПРОВОЖДЕНИЕ ПОВЫШЕНИЯ КВАЛИФИКАЦИИ СОТРУДНИКОВ ФСИН РОССИИ: МНЕНИЕ ЭКСПЕРТНОГО СООБЩЕСТВА, ПРОБЛЕМЫ, УСЛОВИЯ РЕАЛИЗАЦИИ
}

Центральным вопросом статьи является актуализачия педагогического сопровождения повышения квалификации сотрудников ФСНН (Федеральной службы исполнения наказаний) России. Представлено авторское понимание челей и содержания педагогического сопровождения повыиения квалификации сотрудников ФСИН. Авторами проанализированы основнье подходы к проблеме, раскрыты суиностные особенности процесса профессионально-личностного совериенствования. В статье представлены данные экспертного опроса (опыт работы не менее 10 лет на руководящей должности в структуре ФСИН России) по проблемам курсов повыления квалификации сотрудников ФСНН России. Показано, что реализация педагогического сопровождения повышения квалификачии требует создания специальных организационно-педагогических условий, будет способствовать развитию профессионально-личностного потенциала, профессионально-личностному совериенствованию сотрудника и его дальнейшему служебно-профессиональному росту в ФСИН России.

Ключевые слова: УИС (Уголовно-исполнительная система), ФСИН (Федеральная служба исполнения наказаний) России, повышение квалификации, педагогическое сопровождение, профессионально-личностный потенциал, профессионально-личностное совериенствование, служебно-профессиональный рост, экспертный опрос.

\section{Ivan Goynov, Elena Zritneva PEDAGOGICAL SUPPORT OF INCREASE QUALIFICATIONS OF EMPLOYEES OF FPS RUSSIA: OPINION OF THE EXPERT COMMUNITY, PROBLEMS, CONDITIONS OF REALIZATION}

The central issue of the article is the actualization of pedagogical support of advanced training for FPS (Federal Penitentiary Service) employees in Russia. The author's understanding of the goals and content of the pedagogical support of advanced training of FSIN employees is presented. The authors analyzed the main approaches to the problem, revealed the essential features of the process of professional and personal development. The article presents the data of the expert survey (experience of at least 10 years in a managerial position in the structure of the Federal Penitentiary Service of Russia) on the issues of refresher courses for the Federal Penitentiary Service of Russia officers. It is shown that the implementation of pedagogical support of advanced training requires the creation of special organizational and pedagogical conditions, will contribute to the development of professional and personal potential, professional and personal improvement of the employee and his further service and professional growth in the Federal Penitentiary Service of Russia.

Key words: MIS (penitentiary system), FPS (Federal Penitentiary Service) of Russia, advanced training, pedagogical support, professional and personal potential, professional and personal improvement, service and professional growth, expert survey.

Bведение / Introduction. В условиях реформирования уголовно-исполнительной системы (УИС) Российской Федерации и повышения требований к качеству специалистов, выпускаемых вузами МВД и ФСИН России, актуализируется потребность и в изменениях в системе повышения квалификации сотрудников Федеральной службы исполнения наказаний (ФСИН), соответствующих запросам общества в целом и отдельной личности в частности: в приобретении новых зна- 
ний, получении дополнительных импульсов в профессиональной деятельности, способствующих ее успешной реализации, совершенствованию профессионально-личностных качеств и развитию профессионально-личностного потенциала.

В научной литературе последних лет (А. В. Вилкова, А. Ю. Долинин, А. И. Огородников и др.) отмечается, что в условиях реформирования УИС проявляется недостаточная профессиональная подготовка сотрудников по многим показателям, что выступает значимым препятствием проводимых реформ [2; 13]. В связи с этим в работах Б. Н. Казберова, О. Ю. Кичигиной, Т. М. Молоковой, Е. А. Мухтаровой, Н. А. Никулиной, А. И. Огородникова, О. М. Писарева, Е. А. Тимофеевой, О. В. Хомякова, А. П. Шумарова актуализируется необходимость совершенствования программ подготовки и повышения квалификации сотрудников ФСИН России, обеспечивающих качественное функционирование всей отечественной уголовно-исполнительной системы. При этом возникает необходимость педагогического сопровождения повышения квалификации лиц младшего и среднего начальствующего состава ФСИН России для обеспечения адаптации к профессии, развития профессионально-личностного потенциала и дальнейшего служебно-профессионального роста.

В современных условиях система повышения квалификации как звено непрерывного образования человека является гиббой, оперативной и динамичной структурой, представляет собой органическое единство прикладных, фундаментальных и методологических знаний, содержание которых основано на новейших достижениях науки и передового опыта. Как особо востребованная форма последипломного образования, курсы повышения квалификации восполняют недостающие (или устаревшие) знания, формируют актуальные и инновационные профессиональные компетенции, способствуют совершенствованию личности профессионала посредством развития его профессионально-личностного потенциала, обеспечивают профессионально-личностную динамику слушателя (С. Г. Вершловский, Л. В. Коновалова, Ю.В.Кричевский, Ю. Н. Кулюткин, В. Г. Онушкин, Г. С. Сухобская и др.). Последипломное образование характеризует важный этап непрерывного образования, связанный с освоением специалистом новых теоретических и практических знаний и умений, с его развитием как личности и профессионала.

Понятие «педагогическое сопровождение» в процессе становления личности специалиста отражено в работах Г. В. Безюлевой, М. И. Рожкова, Т. П. Даниличевой, Е. М. Муравьева, Ю. Н. Сопильняк, В. Н. Сосниной, И. М. Яковенко и др. Отмечается, что востребованность «педагогического сопровождения» появляется в ситуации неопределенности социальных и деятельностных условий, в ситуации экстремальности, так как это особая форма педагогической помощи, направленная на выявление и развитие профессионально-личностного потенциала и личностного совершенствования.

В частности, педагогическое сопровождение называется необходимым условием успешной профессиональной адаптации, реализации профессионально-личностного потенциала, освоения путей своего профессионального становления и служебно-профессионального продвижения сотрудников ФСИН России (Ю. Н. Сопильняк, В. Н. Соснина) [17; 18]. При этом отмечается явное противоречие между растущими квалификационными требованиями к профессиональной деятельности сотрудников ФСИН и слабой педагогической составляющей повышения их квалификации.

Вопросами формирования профессионально важных качеств (ПВК) и развития профессиональных способностей сотрудников УИС и ФСИН России на разных этапах их профессионализации занимались О. Н. Ежова, А. И. Исмаилов, А. М. Киселев, С. Г. Колесов, Е. В. Попова, Т. А. Симакова, В. В. Фомин и др. Среди основных профессиональных задач сотрудников ФСИН России выделяют: создание и неукоснительное поддержание условий порядка и безопасности в учреждениях, исполняющих уголовные наказания в виде лишения свободы в соответствии с законодательством Российской Федерации; обеспечение охраны прав, свобод и законных интересов осужденных и лиц, содержащихся под стражей; обеспечение контроля за лицами, условно осужденными и осужденными, но с отсрочкой отбывания наказания; организацию трудовой и досуговой деятельности лиц, оказавшихся в местах лишения свободы; осуществление перевос- 
питания лиц, находящихся в пенитенциарных учреждениях, и их социальной адаптации и пр. [9]. При этом следует отметить, что осуществление указанных задач профессиональной деятельности сопровождается экстремальными ситуациями, постоянной психоэмоциональной напряженностью и эмоциональным стрессом, что приводит к быстрому эмоциональному выгоранию, профессиональной деструкции и пр. (А. В. Кученев, Е. Н. Нырков, Т. И. Помыткина, Л. К. Фортова и др.). Данные обстоятельства также актуализируют организацию педагогического сопровождения повышения квалификации сотрудников ФСИН, способствующего их профессионально-личностному совершенствованию посредством развития профессионально-личностного потенциала и, как следствие, служебно-профессиональному продвижению.

Спектр исследований в области профессионально-личностного совершенствования достаточно обширен: изучаются сущность, специфика, стадии профессионализации личности и пр. (А. А. Бодалев, А. А. Деркач, Е. А. Климов, Н. С. Пряжников, В. Д. Шадриков и мн. др.), процессы становления субъекта профессиональной деятельности под влиянием различных факторов и процессов (Б. Г. Ананьев, Л. А. Корастылева, А. К. Маркова, А. А. Реан и др.), условия профессионально-личностного развития и достижения вершин («акме») в профессии (Л. И. Божович, А. А. Деркач, А. В. Карпов, К. В. Кузьмина, Н. Н. Нечаев, Ю. П. Поваренков, В. А. Сластенин и мн. др.) и др.

Особенности психолого-педагогического сопровождения профессионально-личностного развития сотрудников УИС раскрыты в исследованиях Т. П. Даниличевой, Ю. Ю. Железной, Л. С. Качкиной, О. М. Писарева, Я. Н. Поляковой.

Вопросы развития профессионально-личностного потенциала субъекта трудовой деятельности рассматриваются в работах Б. Г. Ананьева, Г. И. Артемьевой, В. Г. Асеева, Б. Г. Юдина, дается его характеристика как саморазвивающейся системы внутренних ресурсов человека.

Необходимо отметить, что профессиональная подготовка сотрудников ФСИН России в научной литературе рассматривается преимущественно в связи с ее программными, содержательно-педагогическими, психолого-педагогическими аспектами (Э. Э. Аллахвердиев, А. А. Вотинов, М. Г. Дебольский, И. И. Дерен,

А. Ю. Кирьянов, В. М. Коровин, Е. А. Корякин, В. В. Прудников, Н. А. Тюгаева и др.). При этом недостаточно изученными оказались вопросы педагогического сопровождения повышения квалификации сотрудников ФСИН России: не разработано комплексно-диагностическое обеспечение формирования профессионально значимых качеств сотрудников ФСИН, нет разработок программ развития профессионально-личностного потенциала специалистов, не проводились контрольно-диагностические исследования процесса профессионального обучения сотрудников ФСИН и их профессионально-личностного совершенствования в процессе повышения квалификации и т. д.

Maтериалы и методы / Materials and methods. На основании сказанного нами была сформулирована цель исследования: актуализация педагогического сопровождения повышения квалификации сотрудников ФСИН России, выявление проблем и организационно-педагогических условий его реализации.

Методологическую основу исследования составили принципы и методы личностно ориентированного, компетентностного, субъектно-деятельностного подходов (Л. С. Выготский, И. А. Зимняя, Н. В. Кузьмина, А. Н. Леонтьев, С. Л. Рубинштейн, В. В. Сафонова и др.).

В работе с материалами были использованы методы системного, контент-анализа, экспертного опроса, анализ документов. Респондентами выступили 36 экспертов - сотрудников ФСИН России с опытом работы не менее 10 лет на руководящей должности в уголовно-исполнительной системе.

Peзультаты и обсуждение / Results and discussion. Логика настоящего исследования предполагает изначальное обрашение к научным исследованиям, в которых рассмотрены вопросы профессионально-личностного развития субъекта в процессе повышения квалификации, так как педагогическое сопровождение повышения квалификации сотрудников ФСИН России ориентировано на максимальное развитие профессионала и его совершенствование посредством активизации профессионально-личностного потенциала. 
Проведенный контент-анализ научных работ позволяет сделать следующие обобщения [1; $3 ; 5 ; 6 ; 11 ; 15$ и др.]:

- проблема профессионально-личностного совершенствования широко освещена в отечественных и зарубежных исследованиях профессионального образования, психологии труда, педагогической психологии, акмеологии, при этом недостаточно изучен педагогический аспект решения проблемы, не обоснованы условия педагогического сопровождения повышения квалификации сотрудников ФСИН в целях профессионально-личностного совершенствования слушателей курсов;

- понятие «профессионально-личностное совершенствование» в работах исследователей используется в качестве характеристики позитивных изменений профессионала, происходящих в процессе деятельности и / или повышении квалификации, как одна из сторон профессионального развития (в противовес деформации / деструкции);

- профессионально-личностное совершенствование как процесс имеет свою стадийность, характеризуется динамикой, длительностью, многоуровневостью;

- профессионально-личностное совершенствование осуществляется в рамках конкретной профессиональной деятельности, задается ее условиями, спецификой, требованиями и др.;

- до сих пор отсутствует единая точка зрения на вопрос о механизмах профессионально-личностного совершенствования в процессе повышения квалификации и функциональном содержании педагогического сопровождения повышения квалификации;

- большинство исследователей отводят важную роль в профессионально-личностном совершенствовании субъектности личности, считая основой совершенствования принцип саморазвития, предопределяющий способности к практическому преображению;

- развитие профессионально-личностного потенциала (реальные профессионально-личностные возможности в совокупности с нереализованными внутренними ресурсами) можно определить в качестве основной задачи педагогического сопровождения повышения квалификации;

- результатом профессионально-личностного совершенствования в разных источниках называется «карьерная успешность», «профессиональная компетентность», достижение «акме», «профессионального мастерства» (М. Г. Горбунов, А. А. Деркач, А. Г. Ковалев, А. К. Маркова, О. Н. Родина, А. В. Хуторской и др.).

Далее, в рамках исследования был проведен экспертный анкетный опрос, выявляющий проблемы повышения квалификации сотрудников ФСИН России. В заочном анонимном анкетировании приняли участие 36 человек. Требования к экспертам: опыт работы не менее 10 лет на руководящей должности в уголовно-исполнительной системе.

Были получены следующие результаты:

- $72 \%$ респондентов отметили проблемы в кадровом обеспечении уголовно-исполнительной системы и необходимость постоянного повышения квалификации сотрудников ФСИН России (в настоящее время необходимая периодичность повышения квалификации сотрудников составляет пять лет);

- $96 \%$ опрошенных считают необходимым условием непрерывного образования потребность в реализации собственного профессионально-личностного потенциала;

- к основным проблемам повышения квалификации сотрудников ФСИН России экспертами отнесены: слабое информирование сотрудников о предлагаемых образовательных услугах, их низкая вариативность; отсутствие разнообразия информации / ее дублирование; низкое финансовое обеспечение условий обучения; потребность в практико-ориентированных формах обучения, отсутствие психолого-педагогического сопровождения повышения квалификации и т. д. (рис. 1). 


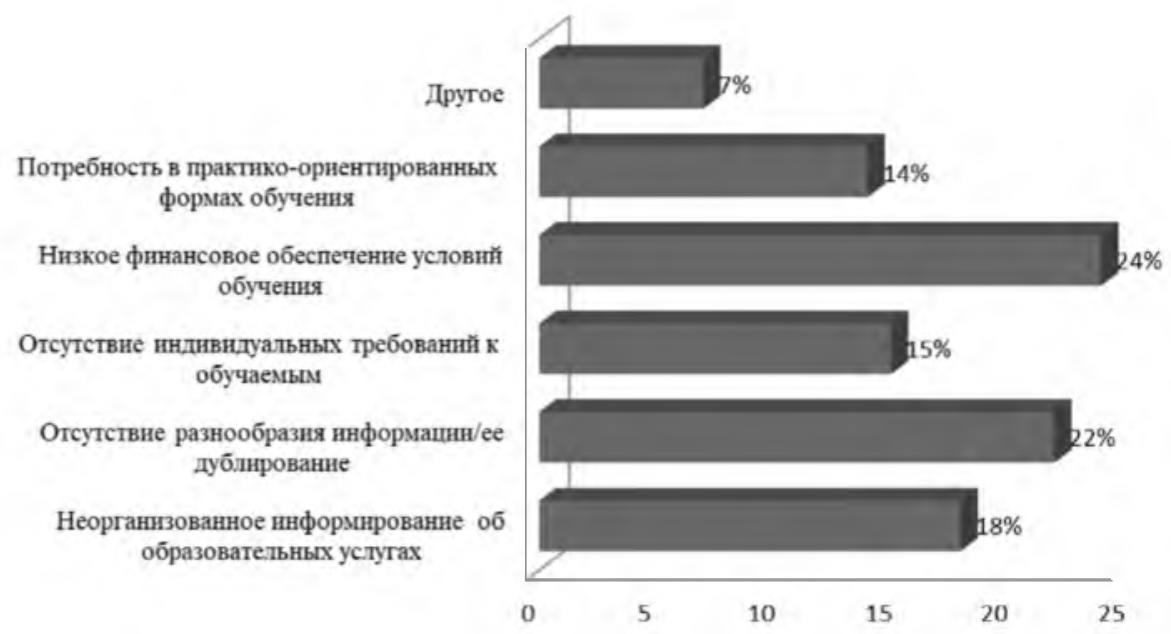

Рис. 1. Проблемы в рамках повышения квалификации, по данным экспертного опроса

Кроме того, более 75 \% экспертов в ходе опроса отметили, что:

- повышение квалификации способствует профессионально-личностному развитию сотрудника ФСИН России, повышению уровня его достижений в профессии и служебно-профессиональному росту;

- высокие карьерные достижения сотрудника соотносятся с высоким уровнем его профессионально-личностного потенциала;

- актуальным для сотрудников ФСИН является повышение коммуникативной, лидерской и управленческой компетентности;

- есть необходимость разработки инструментария мониторинга качества курсов повышения квалификации и диагностических методик развития профессионально-личностного потенциала сотрудника ФСИН;

- наиболее эффективными средствами, методами, технологиями повышения квалификации эксперты видят: разнообразие и интересную подачу материала; прохождение стажировок; организованные встречи со специалистами по смежным областям; необходимость развития субъектной позиции обучаемого; технологии дистанционного обучения без отрыва от профессиональной деятельности; возможность обмена опытом с коллегами из других регионов, в том числе иностранными коллегами (рис. 2).

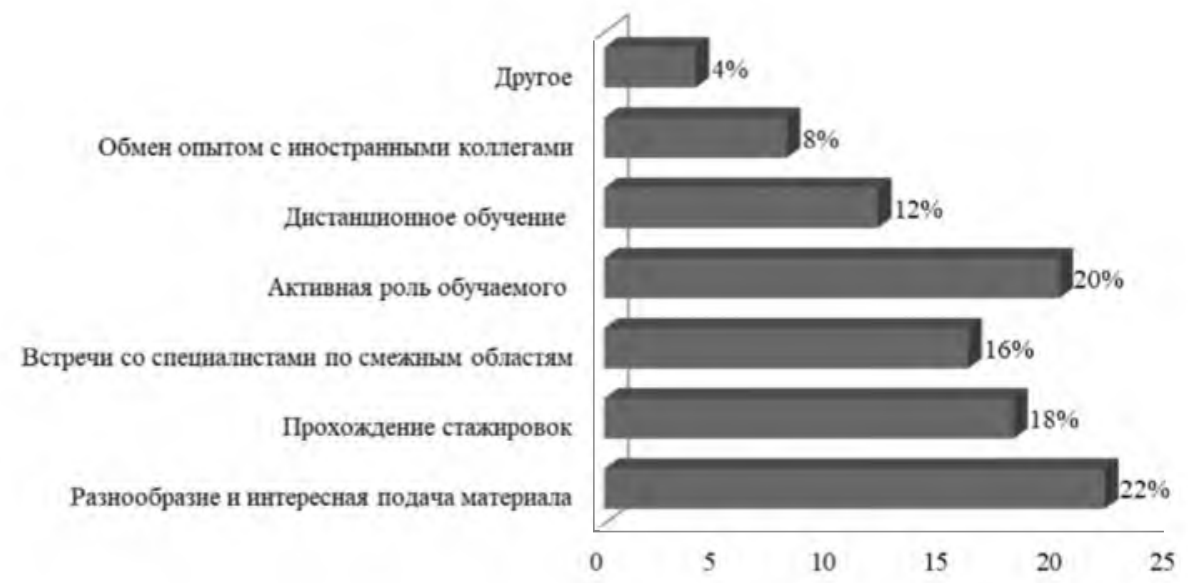

Рис. 2. Эффективные средства и методы повьшения квалификации, способствующие профессионально-личностному развитию 
Большинство экспертов подчеркивали особую важность:

- периодического повышения квалификации с целью развития профессионально-личностного потенциала сотрудников на основе интенсификации приобретения нового знания, расширения спектра профессиональных умений, достижений и т. д.;

- соответствия организационно-содержательных составляющих образовательного процесса современным требованиям повышения качества профессиональной подготовки, индивидуальным особенностям слушателя с учетом специфики служебных задач, векторные направления которых связаны с проблемой профессионального развития;

- использования в процессе обучения методов и средств передачи профессионально-личностного опыта ведущими специалистами в конкретных областях профессиональной деятельности;

- приобретения новых знаний в области организации управления в системе ФСИН, специфики управленческого функционала; выстраивания эффективной коммуникации с коллегами и спецконтингетом.

Анализ рабочих программ повышения квалификации ФКОУ ВО «Пермский институт ФСИН России» показал, что психолого-педагогическим аспектам службы сотрудников на курсах уделяется незначительное внимание, что актуализирует педагогическое сопровождение повышения квалификации. Так, тематический план первоначальной подготовки лиц среднего и старшего начальствующего состава учреждений и органов УИС включает: правовые и организационные основы деятельности УИС (18 ч); огневая подготовка (32 ч); физическая подготовка (30 ч); оказание 1-й помощи (10 ч); основы профессиональной деятельности сотрудников УИС (10 ч). Всего - 110 часов.

В тематический план повышения квалификации начальников караулов отделов охраны исправительных учреждений ФСИН входит: организация охраны в УИС (36 ч); основы деятельности специалистов кинологической службы в учреждениях ФСИН (12 ч); уголовно-исправительное право (8 ч); огневая подготовка (12 ч); трудовое право (10 ч); физическая подготовка (12 ч); делопроизводство (10 ч); психолого-педагогические основы деятельности сотрудников отдела охраны (10 ч). Всего - 110 часов.

Вслед за исследователями М. К. Горшковым, Г. А. Ключаревым [4], О. В. Резиковой, В. Я. Синенко и др. мы считаем повышение квалификации важным этапом (частью) непрерывного профессионально-личностного совершенствования конкретного специалиста - сотрудника ФСИН, как следствие, возможности его служебно-профессионального роста.

Педагогическое сопровождение повышения квалификации сотрудников ФСИН России форма педагогической деятельности, направленная на создание условий для развития профессионального совершенствования посредством развития профессионально-личностного потенциала слушателей и их служебно-профессионального продвижения. Это целостный, системный процесс организации взаимодействия субъектов образовательного процесса, основанный на идеях педагогической поддержки, включающий основные ее виды: диагностику; консультирование, коррекцию профессионально- личностных деформаций.

Под профессионально-личностным совершенствованием сотрудника ФСИН мы понимаем динамичный процесс целостного развития личности как активного участника профессиональной деятельности, обусловленный спецификой этой деятельности, характеризующийся актуализацией и реализацией профессионально-личностного потенциала, позитивным изменением личностных новообразований (параметров / компонентов), профессиональным ростом на разных этапах профессионального становления, в том числе и в процессе повышения квалификации как важном этапе непрерывного совершенствования профессионала.

Организация педагогического сопровождения сотрудников ФСИН на курсах повышения квалификации должна быть построена по такой схеме обучения, которая позволит обучающимся получить не только максимальное количество общетеоретических знаний, а также усилит прак- 
тическое направление подготовки по востребованным перспективным вопросам служебной деятельности, позволит обеспечить профессионально-личностное совершенствование сотрудника, активизирует процессы самоактуализации, саморазвития и др. $[3 ; 7 ; 10 ; 13 ; 14 ; 15$ и др.].

Мы полагаем, что педагогическое сопровождение повышения квалификации сотрудников ФСИН России должно обеспечиваться путем реализации следующих организационно-педагогических мероприятий:

- разработка посредством развития профессионально-личностного потенциала сотрудника ФСИН модели профессионально-личностного совершенствования, которая отражает концептуальные основы, принципы, этапность данного процесса;

- выявление критериев и показателей процесса профессионально-личностного совершенствования в процессе обучения, самообразования;

- комплексная диагностика личности профессионала: ПВК; способностей, знаний, умений и навыков; профессионально-личностного потенциала, способов его актуализации в ходе профессионализации (в частности, в ходе повышения квалификации); степени успешности личности в профессиональной деятельности (профессиональная самоэффективность) и др.;

- $\quad$ реализация блочно-модульной образовательной программы в рамках курсов повышения квалификации, разработанной с учетом требований, предъявляемых к специфике профессионально-личностного развития сотрудника в рамках служебной деятельности;

- дифференцированный подход к слушателям, с учетом их категорий и уровня профессионального мастерства, создание условий для разработки и реализации индивидуальной траектории обучения на основе их потребностей и с учетом профессионально-личностных возможностей;

- реализация гуманистического, субъектного, компетентностного подходов, обеспечивающих условия для самостоятельности, активности субъекта, его инициативности; активизации процессов самооценки, саморефлексии, саморазвития, самоэффективности и т. д.;

- формирование субъектной позиции слушателей, нацеленной на профессионально-личностное саморазвитие;

- использование методов и технологий интерактивного обучения (игровые, тренинговые, дискуссионные, видеолекций, кейс-технологии).

Заключение / Conclusion. Профессионально-личностное совершенствование сотрудника ФСИН есть многогранный феномен, требующий системного изучения; это динамичный процесс целостного развития личности как активного участника профессиональной деятельности, обусловленный спецификой этой деятельности, характеризующийся актуализацией и реализацией профессионально-личностного потенциала, позитивным изменением личностных параметров, профессиональным ростом на разных этапах профессионального становления.

Наиболее эффективными в плане профессионально-личностного совершенствования признаны курсы повышения квалификации, участие в различных формах интерактивной деятельности, самообразование и др.

Успешность процесса профессионально-личностного совершенствования сотрудника ФСИН будет зависеть от четкой организации и планирования, реализации совокупности организационно-педагогических условий в процессе повышения квалификации и стремления сотрудника к саморазвитию и дальнейшему самосовершенствованию.

\section{ЛИТЕРАТУРА И ИНТЕРНЕТ-РЕСУРСЫ}

1. Бордовская Н. В. Профессионально-личностное развитие будущего специалиста как психолого-педагогическая проблема // Известия Российского государственного университета им. А. И. Герцена. 2012. № 145. C. $28-43$. 
2. Вилкова А. В., Смородинскова И. А. Совершенствование профессиональной подготовки сотрудников уголовно-исполнительной системы // Перспективы науки. 2018. № 3(102). С. 84-86.

3. Гойнов И. В. Развитие личностного потенциала сотрудников Федеральной служббы исполнения наказаний в процессе повышения квалификации // Образование как фактор развития интеллектуально-нравственного потенциала личности и современного общества: материалы VI Международной научной конференции. СПб., 2016. С. 366-369.

4. Горшков М. К., Ключарев Г. А. Непрерывное образование в контексте модернизации. М.: ИС РАН, ФГНУ ЦСИ, 2011. 232 с.

5. Деркач А. А. Самоопределение и самоутверждение личности в профессиональной деятельности // Психология музыкальной деятельности: теория и практика / под ред. Г. М. Цыпина. М.: Академия, 2003. C. $336-338$.

6. Зеер Э. Ф. Профессиональное развитие человека в системе непрерывного образования // Профессиональное образование. Столица. 2013. № 9. С. 10-14.

7. Зритнева Е. И. Повышение квалификации сотрудников системы социальной защиты населения Ставропольского края: компетентностный подход // Вестник Северо-Кавказского федерального университета. 2016. №1(52). С. 125-131.

8. Измайлова Е. В. Повышение квалификации сотрудников уголовно-исполнительной системы на основе личностно ориентированного обучения: дис. ... канд. пед. наук. Киров, 2008.

9. Исмаилов А. И. Структура профессионально важных качеств сотрудников уголовно-исполнительной системы // Совершенствование системы подготовки кадров по единоборствам: материалы научно-практической конференции преподавателей кафедры ТиМ единоборств РГУФКСиТ. 2010. С. 93-97.

10. Кичигина О. Ю. Совершенствование профессиональной переподготовки и повышения квалификации сотрудников УИС // Уголовно-исполнительная система сегодня: взаимодействие науки и практики: материалы научно-практической конференции / под ред. А. Г. Антонова. Новокузнецк, 2016. C. $176-178$.

11. Маркова А. К. Психология профессионализма. М.: РАГС. 2006. 308 с.

12. Никулина Н. А. Совершенствование профессиональной подготовки сотрудников УИС // Сборник научных трудов сотрудников Вологодского института права и экономики ФСИН России / под ред. В. Н. Некрасова. Вологда, 2017. С. 182-186.

13. Нырков Е. Н. Акмеологические средства предупреждения личностно-профессиональных деформаций сотрудника ФСИН // Акмеология. 2016. № 51. С. 67.

14. Огородников В. И., Долинин А. Ю. Совершенствование механизма профессионального обучения сотрудников в условиях реформирования УИС // Человек: преступление и наказание. 2010. № 2(67) C. $9-13$.

15. Полякова Я. Н., Симакова Т. А., Фомин В. В. Психолого-педагогические аспекты развития профессионально значимых качеств сотрудников уголовно-исполнительной системы: монография. Рязань, 2015. $160 \mathrm{c}$.

16. Психолого-педагогические проблемы развития личности в системе многоуровневого профессионального образования: коллективная монография / С. С. Асатрян и др.; под ред. Н. П. Клушиной. Ставрополь: СевКавГТУ, 2009. 435 с.

17. Сопильняк Ю. П. Педагогическое сопровождение профессиональной подготовки специалистов в области правоохранительной деятельности: дис. ... канд. пед. наук. Майкоп, 2007. 254 с.

18. Соснина В. Н. Педагогическое сопровождение молодых сотрудников пенитенциарной системы: дис. ... канд. пед. наук. Улан-Удэ, 2011. 199 с.

\section{REFERENCES AND INTERNET RESOURCES}

1. Bordovskaja N. V. Professional'no-lichnostnoe razvitie budushhego specialista kak psihologopedagogicheskaja problema (Professional and personal development of the future specialist as a psychological and pedagogical problem) // Izvestija Rossijskogo gosudarstvennogo universiteta im. A. I. Gercena. 2012. No.145. S. 28-43.

2. Vilkova A. V., Smorodinskova I. A. Sovershenstvovanie professional'noj podgotovki sotrudnikov ugolovnoispolnitel'noj sistemy (Improvement of professional training of employees of the penitentiary system) // Perspektivy nauki. 2018. No. 3(102). S. 84-86. 
3. Gojnov I. V Razvitie lichnostnogo potenciala sotrudnikov federal'noj sluzhby ispolnenija nakazanij $\mathrm{v}$ processe povyshenija kvalifikacii (Professional development of a person in the system of continuing education) // Obrazovanie kak faktor razvitija intellektual'no-nravstvennogo potenciala lichnosti i sovremennogo obshhestva: materialy VI mezhdunarodnoj nauchnoj konferencii. SPb., 2016. S. 366-369.

4. Gorshkov M. K., Kljucharev G. A. Nepreryvnoe obrazovanie v kontekste modernizacii. (Continuing education in the context of modernization). M.: IS RAN, FGNU CSI, 2011. $232 \mathrm{~s}$.

5. Derkach A. A. Samoopredelenie i samoutverzhdenie lichnosti v professional'noj dejatel'nosti (Selfdetermination and self-assertion of personality in professional activity) // Psihologija muzykal'noj dejatel'nosti: teorija i praktika / pod red. G. M. Cypina. M.: Akademija, 2003. S. 336-338.

6. Zeer Je. F. Professional'noe razvitie cheloveka v sisteme nepreryvnogo obrazovanija (Development of personal potential of employees of the Federal penitentiary service in the process of professional development) // Professional'noe obrazovanie. Stolica. 2013. No. 9. S. 10-14.

7. Zritneva E. I. Povyshenie kvalifikacii sotrudnikov sistemy social'noj zashhity naselenija Stavropol'skogo kraja: kompetentnostnyj podhod (Professional development of employees of the social protection system of the Stavropol territory: competence approach) // Vestnik Severo-Kavkazskogo federal'nogo universiteta. 2016. No. 1(52). S. 125-131.

8. Izmajlova E. V. Povyshenie kvalifikacii sotrudnikov ugolovno-ispolnitel'noj sistemy na osnove lichnostno orientirovannogo obuchenija. (Professional development of employees of the penitentiary system on the basis of personality-oriented training): dis. ... kand. ped. nauk. Kirov, 2008.

9. Ismailov A. I. Struktura professional'no vazhnyh kachestv sotrudnikov ugolovno-ispolnitel'noj sistemy (Structure of professionally important qualities of employees of penal system) // Sovershenstvovanie sistemy podgotovki kadrov po edinoborstvam: materialy nauchno-prakticheskoj konferencii prepodavatelej kafedry TiM edinoborstv RGUFKSiT, 2010. S. 93-97.

10. Kichigina O. Ju. Sovershenstvovanie professional'noj perepodgotovki i povyshenija kvalifikacii sotrudnikov UIS (Improvement of professional retraining and advanced training of employees of the MIS) // Ugolovnoispolnitel'naja sistema segodnja: vzaimodejstvie nauki i praktiki: materialy nauchno-prakticheskoj konferencii / pod red. A. G. Antonova. Novokuzneck, 2016. S. 176-178.

11. Markova A. K. Psihologija professionalizma, (Psychology of professionalism) M.: RAGS, 2006, $308 \mathrm{~s}$.

12. Nikulina N. A. Sovershenstvovanie professional'noj podgotovki sotrudnikov UIS (Improving the training of the staff of the MIS) // Sbornik nauchnyh trudov sotrudnikov Vologodskogo instituta prava i jekonomiki FSIN Rossii / pod red. V. N. Nekrasova. Vologda, 2017. S. 182-186.

13. Nyrkov E. N. Akmeologicheskie sredstva preduprezhdenija lichnostno-professional'nyh deformacij sotrudnika FSIN (Akmeological means of preventing the personal and professional deformation employee of the Federal penitentiary service) // Akmeologija. 2016. No. 51. S. 67.

14. Ogorodnikov V. I., Dolinin A. Ju. Sovershenstvovanie mehanizma professional'nogo obuchenija sotrudnikov $\mathrm{v}$ uslovijah reformirovanija UIS (Improvement of the mechanism of professional training of employees in the conditions of reforming of UIS) // Chelovek: prestuplenie i nakazanie. 2010, No. 2(67). S. 9-13.

15. Poljakova Ja. N., Simakova T. A., Fomin V. V. Psihologo-pedagogicheskie aspekty razvitija professional'no znachimyh kachestv sotrudnikov ugolovno-ispolnitel'noj sistemy (Psychological and pedagogical aspects of the development of professionally significant qualities of employees of the penitentiary system): monografija. Rjazan, 2015. $160 \mathrm{~s}$.

16. Psihologo-pedagogicheskie problemy razvitija lichnosti v sisteme mnogourovnevogo professional'nogo obrazovanija (Psychological and pedagogical problems of personality development in the system of multilevel professional educatio): kollektivnaja monografija / S. S. Asatrjan i dr; pod red. N. P. Klushinoj. Stavropol': SevKavGTU, 2009. S. 435.

17. Sopil'njak Ju. P. Pedagogicheskoe soprovozhdenie professional'noj podgotovki specialistov v oblasti pravoohranitel'noj dejatel'nosti, (Pedagogical support of professional training of specialists in the field of law enforcement): dis. ... kand. ped. nauk. Majkop, 2007. $254 \mathrm{~s}$.

18. Sosnina V N. Pedagogicheskoe soprovozhdenie molodyh sotrudnikov penitenciarnoj sistemy, (Pedagogical support of young employees of the penitentiary system): diss. ... kand. ped. Nauk. Ulan-Udje, 2011. $199 \mathrm{~s}$. 


\section{СВЕДЕНИЯ ОБ АВТОРАХ}

Гойнов Иван Владимирович, соискатель кафедры социальных технологий, Северо-Кавказский федеральный университет, г. Ставрополь; преподаватель ФКОУ ВО «Пермский институт федеральной службы исполнения наказаний России», г. Пермь, E-mail: yunna_sorokopud@mail.ru

Зритнева Елена Игоревна, доктор педагогических наук, профессор, заведующий кафедрой социальньх технологий, Северо-Кавказский федеральный университет. г. Ставрополь. E-mail: zritneva@mail.ru

\section{INFORMATION ABOUT AUTHORS}

Ivan Goynov, postgraduate, Department of Social Technologies, North Caucasus Federal University (Stavropol, Russia), senior teacher, Perm Institute of the Federal Penitentiary Service of Russia (Perm, Russia). E-mail: yunna_sorokopud@mail.ru

Elena Zritneva, Head of the Department. Social Technologies, North Caucasus Federal University, Stavropol, Doctor of Pedagogical Sciences, Professor, Stavropol. E-mail: zritneva@imail.ru 